\title{
Neuroprotective effects of microRNA-210 against oxygen-glucose deprivation through inhibition of apoptosis in PC12 cells
}

\author{
JIE QIU, XIAO-YU ZHOU, XIAO-GUANG ZHOU, RUI CHENG, HAI-YING LIU and YONG LI \\ Department of Newborn Infants, Nanjing Children's Hospital of Nanjing Medical University, \\ Nanjing, Jiangsu 210008, P.R. China
}

Received December 13, 2012; Accepted April 10, 2013

DOI: $10.3892 / \mathrm{mmr} .2013 .1431$

\begin{abstract}
Although several reports have demonstrated the specific roles of microRNAs (miRs) in neuronal differentiation, neurogenesis, neural cell specification and neurodevelopmental function, there have been no studies with regard to the importance of miRs in hypoxic-ischemic encephalopathy (HIE). In the present study, we aimed to investigate the effect of miR-210 on neuronal cell apoptosis caused by HI injury. We established an ex vivo model of HIE using oxygen-glucose deprivation (OGD) and demonstrated that miR-210 expression was upregulated in pheochromocytoma (PC12) cells after $4 \mathrm{~h}$ of OGD compared with normoxic controls. Furthermore, miR-210 suppressed cell apoptosis by inhibiting caspase activity and by regulating the balance between $\mathrm{Bcl}-2$ and $\mathrm{Bax}$ levels. In conclusion, the present study revealed that miR-210 exerts neuroprotective effects by inhibiting cell apoptosis. This work represents a potential novel therapeutic approach to combat neonatal HI injury.
\end{abstract}

\section{Introduction}

Hypoxic-ischemic encephalopathy (HIE) is one of the primary causes of cerebral damage and long-term neurological sequelae in the perinatal period in term and preterm infants (1). Moderate to severe HIE occurs at a rate of 1-2 per 1,000 full-term live births, with a total HIE incidence of 3-5 per 1,000 (2-4); in developing countries, the incidence of HIE is up to 10-fold higher (5). Almost $50 \%$ of term-born infants suffering from severe HIE die within weeks of birth, while up to $25 \%$ of the survivors exhibit long-term complications (6), including reductions in cerebellar (7), cortical and hippocampal volumes (8). These reductions are associated in turn with cognitive and behavioral deficits, deficits in the verbal and language domains $(9,10)$,

Correspondence to: Dr Jie Qiu, Department of Newborn Infants, Nanjing Children's Hospital of Nanjing Medical University, No.72 Guangzhou Road, Nanjing, Jiangsu 210008, P.R. China

E-mail: jieqiu@yahoo.cn

Key words: microRNA-210, hypoxic-ischemic encephalopathy, apoptosis, gene therapy a reduced IQ (11), cerebral palsy and mental retardation (12). However, no specific or successful neuroprotective strategies existed until recently. Protecting the brain of a newborn remains a challenging priority and represents an unmet medical need.

Hypoxia, which occurs in the brain when oxygen availability drops below normal levels, is a major cause of perinatal HI injury and plays a central role in its pathogenesis. Additionally, insufficient blood flow to the brain, known as brain ischemia, may lead to a poor oxygen supply. The molecular mechanisms underlying the brain's response to oxygen deprivation are extremely complex. Hypoxia inducible factor-1 $\alpha$ (HIF-1 $\alpha)(13-18)$ is a transcription factor that is crucial for normal brain development and in the development of injuries. MicroRNAs (miRs), small (18-25 nts), non-coding RNAs that regulate gene expression by blocking the translation of target mRNAs or by accelerating their degradation, have recently been reported to be induced by hypoxia (19). In particular, miR-210, which is activated by HIF-1 $\alpha$ (20), is a unique miR that has been evolutionarily conserved and ubiquitously expressed in hypoxic cell and tissue types (21-27). While miR-210 was initially considered to be intergenic, a more recent study has revealed that it is contained within the sequence of a hypoxia-inducible transcript with an unknown function (AK123483) (28). miR-210 plays multiple critical roles in the cellular regulation of responses to low oxygen levels, including during ischemic brain injury. Recent studies using a rat model have suggested that miR-210 is expressed in both the brain and blood of middle cerebral artery occlusions (MCAOs) (29,30). Fasanaro et al (31) demonstrated that miR-210 was a critical element in endothelial cell function in response to hypoxia and that it had considerable influence on migration, capillary network formation and differentiation capabilities. Therefore, we hypothesized that miR-210 may play an essential role in HIE, which would identify miR-210 as a potential therapeutic target.

In order to understand the mechanisms of neuronal cell death after HI injury and to identify potential protective agents, an in vitro cell culture model using rat pheochromocytoma (PC12) cells has been previously developed to mimic HI-induced cell death (32) using oxygen-glucose deprivation (OGD). This OGD model was extensively employed to understand the importance of the modulation of cell death pathways in neuroprotection $(33,34)$. In this study, we investigated the effect of miR-210 on neuronal cell apoptosis caused by HI injury. 


\section{Materials and methods}

Cell culture. Rat PC12 cells were obtained from the American Tissue Culture Collection (Rockville, MD, USA) and cultured in DMEM supplemented with $10 \% \mathrm{v} / \mathrm{v}$ horse serum (HS), $5 \% \mathrm{v} / \mathrm{v}$ fetal bovine serum (FBS) and appropriate antibiotics in a humidified chamber $\left(5 \% \mathrm{CO}_{2}\right.$ and $\left.37^{\circ} \mathrm{C}\right)$. The study was approved by the ethics committee of Nanjing Children's Hospital of Nanjing Medical University (Nanjing, China).

miRNA transfection. Fifty microliters of pre-miR hsa-miR-210 or pre-miR-negative control \#1 (pre-miR-NC1; Ambion, Foster City, CA, USA) in OptiMEM I (Invitrogen, Carlsbad, CA, USA), with a final concentration of $100 \mathrm{nM}$, was mixed with $50 \mu 1$ Lipofectamine 2000 (Invitrogen; 25X dilution in OptiMEM I) and incubated at room temperature for $20 \mathrm{~min}$, prior to being added to each well of a 24-well plate (100 $\mu \mathrm{l}$ per well). PC12 cells ( $400 \mu 1$ of $6.25 \times 10^{5}$ cells $\left./ \mathrm{ml}\right)$ were subsequently added to each well. The transfection mixture was incubated $\left(5 \% \mathrm{CO}_{2}\right.$ and $\left.37^{\circ} \mathrm{C}\right)$ for $24 \mathrm{~h}$, and the cells were either used immediately in assays or the media was replaced (500 $\mu \mathrm{l} \mathrm{DMEM/10 \%} \mathrm{v/v} \mathrm{HS/5 \%} \mathrm{v/v} \mathrm{FBS)} \mathrm{and} \mathrm{incubated}$ further.

$O G D$. PC12 cells were washed once with glucose-free DMEM previously bubbled through with a mixture of $95 \%$ nitrogen and $5 \% \mathrm{CO}_{2}$. Cells were maintained in this deoxygenated glucose-free medium. The plates were then placed in a modular incubation chamber (Billups-Rothenberg, Del Mar, CA, USA) and flushed with $95 \%$ nitrogen $/ 5 \% \mathrm{CO}_{2}$ for $4 \mathrm{~min}$ at a flow rate of $10 \mathrm{l} / \mathrm{min}$. The chamber was then sealed and kept in an incubator for $4 \mathrm{~h}$ at $37^{\circ} \mathrm{C}$. Control cells were washed with glucose-containing DMEM and incubated in a normoxic incubator for $4 \mathrm{~h}$.

Real-time quantitative PCR. Total RNA was prepared using TRIzol (Invitrogen). miR was purified using the mirVana kit according to the manufacturer's instructions (Applied Biosystems, Foster City, CA, USA). Using a specific miR-210 and endogenous control U6 stem-loop primer, reverse transcription was performed according to the manufacturer's instructions for the TaqMan miRNARTkit(Applied Biosystems). Total RNA (10 ng) was reverse transcribed to cDNA with $1 \mathrm{mM}$ dNTPs (with dTTP), 50 units reverse transcriptase (RT; $1 \mu \mathrm{l}$ ), 4 units RNase inhibitor in the presence of specific miR-210 or U6 stem loop RT primers in a $15 \mu \mathrm{l}$ system buffered by RT Buffer and diethyl-pyrocarbonate (DEPC) water. Following the thermal cycle program of $16^{\circ} \mathrm{C}$ for $30 \mathrm{~min}, 42^{\circ} \mathrm{C}$ for $30 \mathrm{~min}$ and $85^{\circ} \mathrm{C}$ for $5 \mathrm{~min}$, cDNA was stored at $-20^{\circ} \mathrm{C}$. Real-time quantitative PCR was performed by a fast real-time PCR system (7900HT, Applied Biosystems) using a TaqMan miRNA assay kit. The $20 \mu \mathrm{l}$ reaction volume contained the following components: miR-210 or U6 RT reaction product $(1.33 \mu \mathrm{l}), 20 \mathrm{X}$ TaqMan ${ }^{\circledR}$ MicroRNA assay (miR-210 or U6; $1 \mu \mathrm{l}$ ), TaqMan 2X universal PCR master mix (10 $\mu \mathrm{l})$ and DEPC water $(7.67 \mu \mathrm{l})$. A 96-well plate was then run using the following protocol: $95^{\circ} \mathrm{C}$ for $10 \mathrm{~min}$, followed by 43 cycles of $95^{\circ} \mathrm{C}$ for $15 \mathrm{sec}$ and $60^{\circ} \mathrm{C}$ for $1 \mathrm{~min}$. Finally, the relative miR-210 level was normalized to the endogenous control U6 expression for each sample in triplicate and calculated using the $2^{-\Delta \mathrm{Ct}}$ method.

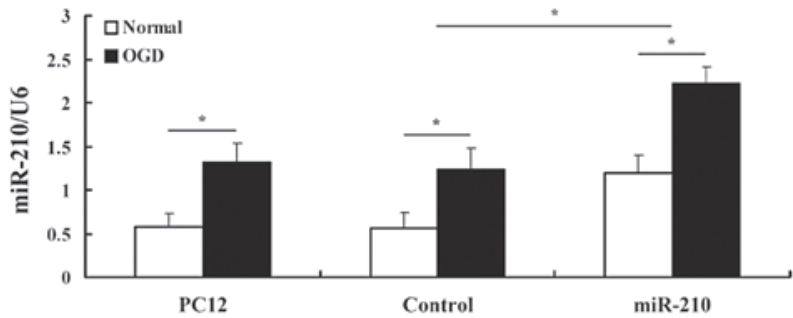

Figure 1. microRNA-210 (miR-210) expression was upregulated in cells after $4 \mathrm{~h}$ of exposure to OGD compared with normoxic conditions (Normal). miR210 was upregulated in PC12 cells transfected with miR-210 vector (miR-210) and compared with non-transfected PC12 cells and cells transfected with the negative control vector (Control). Values shown are the means \pm SD of three independent experiments performed in triplicate $\left({ }^{*} \mathrm{P}<0.05\right)$. OGD, oxygen-glucose deprivation; PC12, pheochromocytoma.

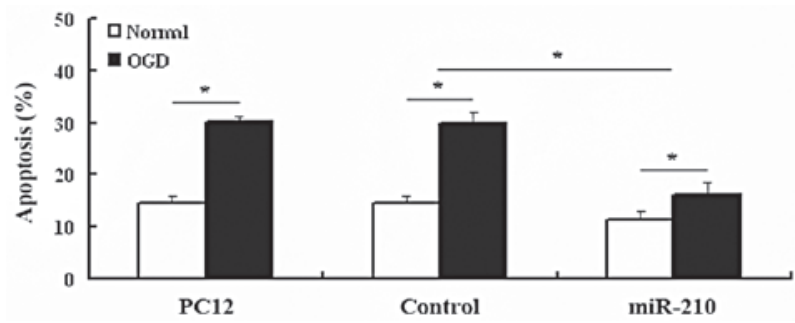

Figure 2. Effects of microRNA-210 (miR-210) on cell apoptosis Apoptosis was upregulated in cells after $4 \mathrm{~h}$ of exposure to OGD compared with cells in normoxic conditions (Normal). Apoptosis was downregulated in cells transfected with miR-210 vector (miR-210) and compared with non-transfected PC12 cells or cells transfected with negative control vector (Control). Values shown are the means \pm SD of three independent experiments performed in triplicate $\left({ }^{*} \mathrm{P}<0.05\right)$. OGD, oxygen-glucose deprivation; PC12, pheochromocytoma.

Evaluation of apoptotic index. Cells were harvested using trypsin/EDTA, washed with PBS, resuspended in $100 \mu \mathrm{l}$ binding buffer and stained with $5 \mu 1$ annexin V-FITC and $1 \mu \mathrm{l}$ propidium iodide (PI) at room temperature for $1 \mathrm{~min}$ (Biovision, Milpitas, CA, USA). The fluorescence of FITC and PI was analyzed using flow cytometry after adding $400 \mu \mathrm{l}$ binding buffer.

Western blot analysis. Cells were washed with ice-cold PBS and lysed in protein lysis buffer $(50 \mathrm{mM}$ Tris, $150 \mathrm{mM} \mathrm{NaCl}$, $10 \mathrm{mM}$ EDTA, $1 \%$ Triton X-100, $200 \mathrm{mM} \mathrm{NaF}$ and $4 \mathrm{mM}$ sodium orthovanadate-containing protease inhibitors; $\mathrm{pH}$ 7.5) for $1 \mathrm{~h}$ on ice. Proteins were quantified using the bicinchoninic acid (BCA) protein assay kit (Pierce, Rockford, IL, USA) according to the manufacturer's instructions. After separation by $10 \%$ sodium dodecyl sulfate-polyacrylamide gel electrophoresis (SDS-PAGE), the proteins ( $20 \mu \mathrm{g} / \mathrm{lane})$ were electrophoretically transferred onto a nitrocellulose membrane (Whatman, London, UK), which was blocked with non-fat dry milk in buffer. The membrane was incubated with primary antibodies against caspase-3, caspase-9, Bax and Bcl-2 (Santa Cruz Biotechnology, Inc., Santa Cruz, CA, USA) and goat anti-mouse IgG conjugated with horseradish peroxidase secondary antibody (Santa Cruz Biotechnology, Inc.). Thereafter, the proteins were visualized by an electrochemiluminescence detection system (GE Healthcare Bio-Sciences, Uppsala, Sweden) and analyzed using Quantity One Analysis Software (Bio-Rad 

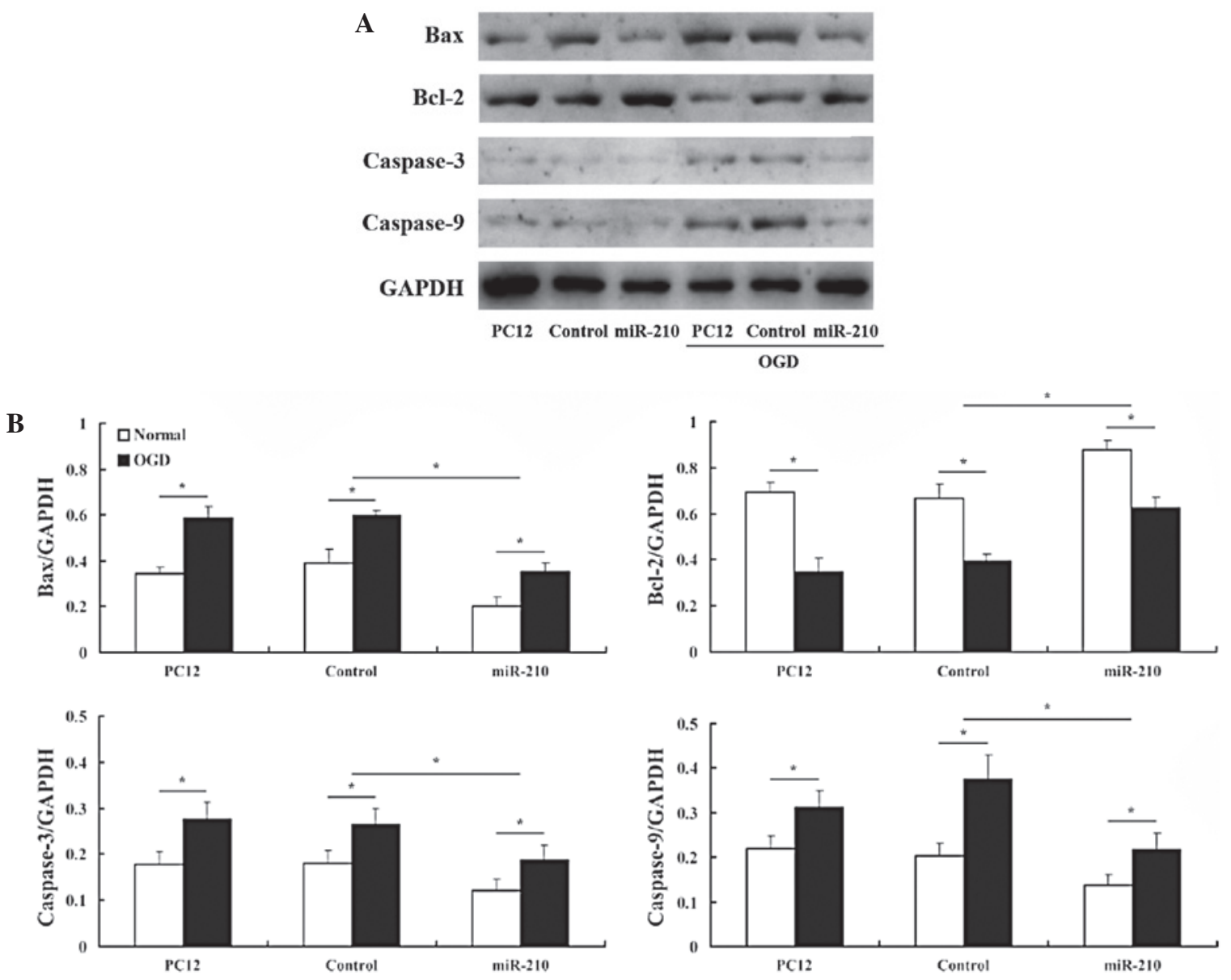

Figure 3. Effects of microRNA-210 (miR-210) on protein expression of caspase-3, caspase-9, Bax and Bcl-2. (A) Caspase-3, caspase-9 and Bax protein levels were decreased in cells that overexpressed miR-210 (miR-210) compared with PC12 cells (PC12) or controls (Control). By contrast, anti-apoptotic Bcl-2 expression was increased in miR-210 overexpression cells compared with PC12 cells or controls. (B) Values represent densitometric analysis of those obtained from three independent experiments. Density values shown are the means $\pm \mathrm{SD}\left({ }^{*} \mathrm{P}<0.05\right)$. Normal, cells in normoxic conditions; OGD, oxygen-glucose deprivation; PC12, pheochromocytoma.

Laboratories, Hercules, CA, USA). $\beta$-actin was used as a protein loading control.

Statistical analysis. All data are expressed as the mean \pm SD. Statistical analysis was performed using the Student's t-test of the SPSS 10.0 statistical software package (SPSS, Chicago, IL, USA). $\mathrm{P}<0.05$ was considered to indicate a statistically significant difference.

\section{Results}

miR-210 expression. We confirmed the expression level of miR-210 using quantitative real-time PCR. U6 was used as the endogenous control since it was the most stably expressed miR in both the control and experimental groups. miR-210 was robustly upregulated in cells transfected with the miR-210 vector, which confirmed a successful preparation. A clear upregulation in miR-210 expression was detected in cells after $4 \mathrm{~h}$ of exposure to OGD, revealing that hypoxia induces the expression of miR-210 in PC12 cell lines (Fig. 1).

Effects of miR-210 on cell apoptosis. Cells subjected to OGD demonstrated a higher cell death rate compared with control cells that were not deprived of glucose and had been kept under normoxic conditions (Fig. 2). However, cells overexpressing miR-210 demonstrated reduced apoptosis after OGD, indicating that miR-210 protects PC12 cells from OGD-induced cell death.

Effects of miR-210 on protein expression of caspase-3, caspase-9, Bax and Bcl-2. We assessed the effects of miR-210 on apoptosis-related protein expression. Western blot analysis demonstrated that Bax, caspase-3 and caspase- 9 protein levels decreased in cells that overexpressed miR-210 compared with controls. By contrast, anti-apoptotic Bcl-2 expression behaved in an almost inverse manner (Fig. 3).

\section{Discussion}

miRs are a recently discovered class of naturally occurring, non-coding RNA molecules that negatively regulate eukaryotic gene expression by binding to complementary sequences in the 3'-untranslated region (3'UTR) of target mRNA. There are $>400$ known human miRs and $>1000$ predicted miR sequences awaiting confirmation (35). The current theory suggests that $10-30 \%$ of all human genes are targets for miR regulation. miRs have roles in almost all aspects of cell biology, including development, apoptosis, proliferation, adipocyte differentia- 
tion, hematopoiesis and exocytosis, and their deregulation has been reported in various diseases, most notably in cancer (36). Although several reports have demonstrated the role of specific miRs in neuronal differentiation, neurogenesis, neural cell specification and neurodevelopmental function (37-39), no report is available on the importance of miRs in HIE.

Recently, a specific group of hypoxia- and HIF-1 $\alpha$-regulated miRs were identified; among them was miR-210, which was found to be important for cell survival in a hypoxic microenvironment (40), cell cycle regulation (41), DNA damage and repair (42) and compromised mitochondrial function. However, no report has revealed its functional relevance in HIE thus far. To the best of our knowledge, this is the first study to utilize the OGD model to investigate the link between miR-210 and HI injury.

miR-210 is currently regarded as the master miR of the hypoxic response, as it has been found to be upregulated by hypoxia in all cell types tested to date (20). Consistent with these data, our results also demonstrated that miR-210 expression was upregulated in PC12 cells after $4 \mathrm{~h}$ of exposure to OGD. Thus, the expression of miR-210 may increase during HIE and its expression in vivo requires further characterization.

During normal brain development, redundant neurons are removed via apoptosis; this is an important physiological process to ensure the formation of appropriate neuronal networks. However, after HI injury, this apoptotic component is pathological and leads to excessive neuronal loss. Previous studies have revealed that miR-210 protects cells from hypoxia-induced apoptosis $(31,40,43)$. Similarly, our data also revealed that $\mathrm{miR}-210$ expression within the first $4 \mathrm{~h}$ after OGD is able to prevent cell apoptosis. Thus, we reason that miR-210 may contribute to modulating the cell apoptotic response to HIE. There are limitations to the therapeutic treatments for HIE, particularly anesthetics and anti-epileptic agents, due to the fact that they induce pathological neural apoptosis in the immature brain (44-47). Furthermore, the blood-brain barrier (BBB) has been shown to be more permeable to various blood-borne solutes and small lipid-insoluble molecules in the fetal rat brain than in adults. As miRs are only $18-25 \mathrm{nts}$ in length, they readily cross the BBB to the HI area $(48,49)$. Although further studies are required, we can conclude that miR-210 delivery via blood circulation may be a novel avenue for therapeutic interventions to combat HIE.

Apoptosis involves a series of gene activation, expression and regulation events. For example, apoptosis is mediated by Bcl-2 family protein members. Bcl-2 pro-survival proteins negatively regulate pro-apoptotic Bax proteins via interactions between their Bcl-2 homology $(\mathrm{BH})$ domains. The role of individual caspases in the developing brain is not fully understood. Genetic analysis revealed that caspase- 3 and caspase- 9 execute programmed cell death in the central nervous system $(50,51)$. Western blot analysis in the present study revealed that caspase-3, caspase-9 and Bax protein levels decreased and Bcl-2 expression increased in cells overexpressing miR-210, which suggests that miR-210 suppressed neuronal apoptosis by inhibiting caspase activity and regulating the balance between Bcl-2 and Bax levels.

In conclusion, this study demonstrated the effect of miR-210 on neuronal cell apoptosis following OGD. However, HI injury-induced events in the brain are extremely complex and further studies are required to clarify the exact mechanism by which miR-210 inhibits cell apoptosis in HIE in vivo.

\section{Acknowledgements}

This project was supported by grants from the Science and Technology Development Project of Nanjing, China (No. 201001090), the Medical Science and Technology Development Project of Nanjing Health Bureau, China (No. YKK10046).

\section{References}

1. du Plessis AJ and Volpe JJ: Perinatal brain injury in the preterm and term newborn. Curr Opin Neurol 15: 151-157, 2002.

2. Gonzalez FF and Ferriero DM: Therapeutics for neonatal brain injury. Pharmacol Ther 120: 43-53, 2008.

3. Shankaran S and Laptook AR: Hypothermia as a treatment for birth asphyxia. Clin Obstet Gynecol 50: 624-635, 2007.

4. Whitelaw A and Thoresen M: Clinical trials of treatments after perinatal asphyxia. Curr Opin Pediatr 14: 664-668, 2002.

5. Lawn JE, Cousens S and Zupan J; Lancet Neonatal Survival Steering Team: 4 million neonatal deaths: when? Where? Why? Lancet 365: 891-900, 2005.

6. Fotopoulos S, Pavlou K, Skouteli H, Papassotiriou I, Lipsou N and Xanthou M: Early markers of brain damage in premature low-birth-weight neonates who suffered from perinatal asphyxia and/or infection. Biol Neonate 79: 213-218, 2001.

7. Allin M, Matsumoto H, Santhouse AM, et al: Cognitive and motor function and the size of the cerebellum in adolescents born very pre-term. Brain 124: 60-66, 2001.

8. Isaacs EB, Edmonds CJ, Chong WK, Lucas A, Morley R and Gadian DG: Brain morphometry and IQ measurements in preterm children. Brain 127: 2595-2607, 2004.

9. CasiroOG,ModdemannDM,StanwickRS,Panikkar-ThiessenVK, Cowan $\mathrm{H}$ and Cheang MS: Language development of very low birth weight infants and fullterm controls at 12 months of age. Early Hum Dev 24: 65-77, 1990.

10. Marlow N, Rose AS, Rands CE and Draper ES: Neuropsychological and educational problems at school age associated with neonatal encephalopathy. Arch Dis Child Fetal Neonatal Ed 90: F380-F387, 2005.

11. Steinman KJ, Gorno-Tempini ML, Glidden DV, et al: Neonatal watershed brain injury on magnetic resonance imaging correlates with verbal IQ at 4 years. Pediatrics 123: 1025-1030, 2009.

12. Tioseco JA, Aly H, Essers J, Patel K and El-Mohandes AA: Male sex and intraventricular hemorrhage. Pediatr Crit Care Med 7: 40-44, 2006.

13. Bacon AL and Harris AL: Hypoxia-inducible factors and hypoxic cell death in tumour physiology. Ann Med 36: 530-539, 2004

14. Gordan JD and Simon MC: Hypoxia-inducible factors: central regulators of the tumor phenotype. Curr Opin Genet Dev 17: $71-77,2007$

15. Gruber M and Simon MC: Hypoxia-inducible factors, hypoxia, and tumor angiogenesis. Curr Opin Hematol 13: 169-174, 2006.

16. Harris AL: Hypoxia - a key regulatory factor in tumour growth. Nat Rev Cancer 2: 38-47, 2002.

17. Kim JW, Tchernyshyov I, Semenza GL and Dang CV: HIF-1-mediated expression of pyruvate dehydrogenase kinase: a metabolic switch required for cellular adaptation to hypoxia. Cell Metab 3: 177-185, 2006.

18. Koumenis C: ER stress, hypoxia tolerance and tumor progression. Curr Mol Med 6: 55-69, 2006.

19. Pocock R: Invited review: decoding the microRNA response to hypoxia. Pflugers Arch 461: 307-315, 2011.

20. Ivan M, Harris AL, Martelli F and Kulshreshtha R: Hypoxia response and microRNAs: no longer two separate worlds. J Cell Mol Med 12: 1426-1431, 2008

21. Chan SY and Loscalzo J: MicroRNA-210: a unique and pleiotropic hypoxamir. Cell Cycle 9: 1072-1083, 2010.

22. Chan SY, Zhang YY, Hemann C, Mahoney CE, Zweier JL and Loscalzo J: MicroRNA-210 controls mitochondrial metabolism during hypoxia by repressing the iron-sulfur cluster assembly proteins ISCU1/2. Cell Metab 10: 273-284, 2009. 
23. Chen Z, Li Y,Zhang H,Huang P and Luthra R: Hypoxia-regulated microRNA-210 modulates mitochondrial function and decreases ISCU and COX10 expression. Oncogene 29: 4362-4368, 2010.

24. Favaro E, Ramachandran A, McCormick R, et al: MicroRNA-210 regulates mitochondrial free radical response to hypoxia and krebs cycle in cancer cells by targeting iron sulfur cluster protein ISCU. PLoS One 5: e10345, 2010.

25. Huang X, Ding L, Bennewith KL, et al: Hypoxia-inducible mir-210 regulates normoxic gene expression involved in tumor initiation. Mol Cell 35: 856-867, 2009.

26. Kushibiki T: Photodynamic therapy induces microRNA-210 and -296 expression in HeLa cells. J Biophotonics 3: 368-372, 2010.

27. Pulkkinen K, Malm T, Turunen M, Koistinaho J and Ylä-Herttuala S: Hypoxia induces microRNA miR-210 in vitro and in vivo ephrin-A3 and neuronal pentraxin 1 are potentially regulated by miR-210. FEBS Lett 582: 2397-2401, 2008.

28. Camps C, Buffa FM, Colella S, et al: hsa-miR-210 Is induced by hypoxia and is an independent prognostic factor in breast cancer. Clin Cancer Res 14: 1340-1348, 2008

29. Jeyaseelan K, Lim KY and Armugam A: MicroRNA expression in the blood and brain of rats subjected to transient focal ischemia by middle cerebral artery occlusion. Stroke 39: 959-966, 2008.

30. Liu DZ, Tian Y, Ander BP, et al: Brain and blood microRNA expression profiling of ischemic stroke, intracerebral hemorrhage, and kainate seizures. J Cereb Blood Flow Metab 30: 92-101, 2010

31. Fasanaro P, D'Alessandra Y, Di Stefano V, et al: MicroRNA-210 modulates endothelial cell response to hypoxia and inhibits the receptor tyrosine kinase ligand Ephrin-A3. J Biol Chem 283: $15878-15883,2008$

32. Tabakman R, Lazarovici P and Kohen R: Neuroprotective effects of carnosine and homocarnosine on pheochromocytoma $\mathrm{PC} 12$ cells exposed to ischemia. J Neurosci Res 68: 463-469, 2002.

33. Guo G and Bhat NR: p38alpha MAP kinase mediates hypoxia-induced motor neuron cell death: a potential target of minocycline's neuroprotective action. Neurochem Res 32 : 2160-2166, 2007.

34. Tabakman R, Jiang H, Schaefer E, Levine RA and Lazarovici P: Nerve growth factor pretreatment attenuates oxygen and glucose deprivation-induced c-Jun amino-terminal kinase 1 and stress-activated kinases p38alpha and p38beta activation and confers neuroprotection in the pheochromocytoma PC12 Model. J Mol Neurosci 22: 237-250, 2004.

35. Griffiths-Jones S, Grocock RJ, van Dongen S, Bateman A and Enright AJ: miRBase: microRNA sequences, targets and gene nomenclature. Nucleic Acids Res 34: D140-D144, 2006.

36. Lee YS and Dutta A: MicroRNAs in cancer. Annu Rev Pathol 4 199-227, 2009.
37. Kim J, Krichevsky A, Grad Y, et al: Identification of many microRNAs that copurify with polyribosomes in mammalian neurons. Proc Natl Acad Sci USA 101: 360-365, 2004.

38. Kosik KS and Krichevsky AM: The Elegance of the MicroRNAs: A Neuronal Perspective. Neuron 47: 779-782, 2005.

39. Schratt GM, Tuebing F, Nigh EA, et al: A brain-specific microRNA regulates dendritic spine development. Nature 439 283-289, 2006

40. Kulshreshtha R, Ferracin M, Wojcik SE, et al: A microRNA signature of hypoxia. Mol Cell Biol 27: 1859-1867, 2007.

41. Giannakakis A, Sandaltzopoulos R, Greshock J, et al: miR-210 links hypoxia with cell cycle regulation and is deleted in human epithelial ovarian cancer. Cancer Biol Ther 7: 255-264, 2008.

42. Crosby ME, Kulshreshtha R, Ivan M and Glazer PM: MicroRNA regulation of DNA repair gene expression in hypoxic stress. Cancer Res 69: 1221-1229, 2009.

43. Hu S, Huang M, Li Z, et al: MicroRNA-210 as a novel therapy for treatment of ischemic heart disease. Circulation 122: S124-S131, 2010.

44. Bittigau P, Sifringer M, Genz K, et al: Antiepileptic drugs and apoptotic neurodegeneration in the developing brain. Proc Natl Acad Sci USA 99: 15089-15094, 2002.

45. Ikonomidou C, Bosch F, Miksa M, et al: Blockade of NMDA receptors and apoptotic neurodegeneration in the developing brain. Science 283: 70-74, 1999.

46. Jevtovic-Todorovic V, Hartman RE, Izumi Y, et al: Early exposure to common anesthetic agents causes widespread neurodegeneration in the developing rat brain and persistent learning deficits. J Neurosci 23: 876-882, 2003.

47. Sanders RD, Ma D, Brooks P and Maze M: Balancing paediatric anaesthesia: preclinical insights into analgesia, hypnosis, neuroprotection, and neurotoxicity. Br J Anaesth 101: 597-609, 2008.

48. Pardridge WM: Intravenous, non-viral RNAi gene therapy of brain cancer. Expert Opin Biol Ther 4: 1103-1113, 2004.

49. Pardridge WM: shRNA and siRNA delivery to the brain. Adv Drug Deliv Rev 59: 141-152, 2007.

50. Kuida K, Haydar TF, Kuan CY, et al: Reduced apoptosis and cytochrome c-mediated caspase activation in mice lacking caspase 9. Cell 94: 325-337, 1998.

51. Kuida K, Zheng TS, Na S, et al: Decreased apoptosis in the brain and premature lethality in CPP32-deficient mice. Nature 384: 368-372, 1996. 